
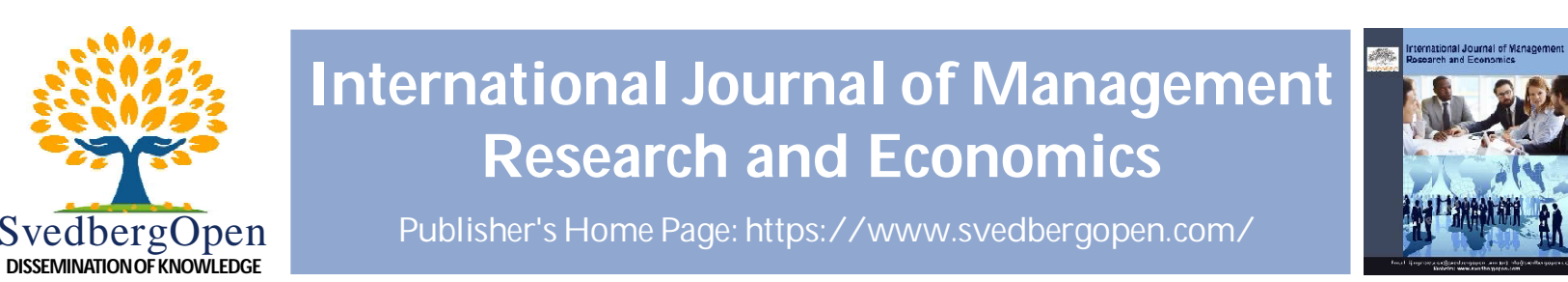

\title{
How SIPTA overlooked Keynes's major contributions to imprecise probability and decision making, 1999-2019
}

Michael Emmett Brady ${ }^{1 *}$

${ }^{1}$ Adjunct Lecturer, California State University, Dominguez Hills, College of Business Administration and Public Policy,Department of Operations Management, 1000 East Victoria St., Carson, California 90747, USA. E-mail: mandmbrady@juno.com

\section{Article Info}

Volume 1, Issue 3, July 2021

Received : 10 January 2021

Accepted : 17 June 2021

Published : 05 July 2021

doi: 10.51483/IJMRE.1.3.2021.11-21

\begin{abstract}
The SIPTA (Society for Imprecise Probability, Theory and Application) view of Keynes's contributions to imprecise probability and application form a one-to-one, onto mapping from the claims of Henry E Kyburg to what is the accepted as being what Keynes's contribution was. Thus, if one is familiar with Kyburg's assessment of Keynes's contributions, then one also knows what SIPTA's views of Keynes's contributions are. There is an extremely severe problem here, however, because Kyburg never read beyond chapter 6 in Keynes's A Treatise on Probability. Kyburg was, therefore, ignorant about the many technical and mathematical contributions made to the theory of imprecise probability by Keynes, such as upper and lower probabilities, non-additive probabilities, sub additive probabilities, interval valued estimates, decision weights, etc., in Parts II, III, IV and V of the A Treatise on Probability. Keynes's applications of non-additive probability appear in his analysis of uncertainty in the theory of the liquidity preference approach to the rate of interest, where uncertainty was defined as an inverse function of the evidential weight of the argument in footnote 1 on page 148 of chapter 12 of the General theory, which Keynes greatly emphasized in his correspondence with Townshend in 1937-38. Kyburg's view of Keynes's contribution was to argue, based on Keynes's verbal discussions on pp.30-34 of chapter III of Keynes's A Treatise on Probability, that Keynes had been the first to (a) define a partial order and (B) the first to argue that all probabilities were not comparable and measurable. Kyburg also acknowledged Keynes's contribution in chapter 6 concerning the weight of the argument as it related to the Bayesian refusal to give any importance to questions dealing with the relative strength of the evidence of different probabilities, i.e., whether the evidentiary base supporting a probability estimate was composed of strong evidence or made up of weak evidence. We will conclude that this assessment of Kyburg's is identical to the SIPTA assessment made from 1999 (Kyburg's 1999 assessment for SIPTA) to the last SIPTA meeting in 2019 (SIPTA, 2015 as an example).
\end{abstract}

Keywords: Non-numerical probabilities, Non (sub) additive probabilities, Decision weights, Lower and upper probabilities, Imprecise probability, Inexact and approximate probabilities

C 2021 Michael Emmett Brady. This is an open access article under the CC BY license (https://creativecommons.org/licenses/by/4.0/), which permits unrestricted use, distribution, and reproduction in any medium, provided you give appropriate credit to the original author(s) and the source, provide a link to the Creative Commons license, and indicate if changes were made.

\section{Introduction}

The paper will be organized in the following fashion. Section two will examine Kyburg's (1970, 1988, 1991, 1992, 1995, 1999, 2002, 2003, 2011) very incomplete and severely deficient assessment of Keynes's contributions (1921, 1973a,

\footnotetext{
* Corresponding author: Michael Emmett Brady, Adjunct Lecturer, California State University, Dominguez Hills, College of Business Administration and Public Policy, Department of Operations Management, 1000 East Victoria St., Carson, California 90747, USA. E-mail: mandmbrady@juno.com
} 
1973b) to imprecise probability theory. Section three will examine the assessments made by members of SIPTA (Society for Imprecise Probability, Theory and Application) of Keynes and show that their assessments of Keynes are identical to those of Kyburg. This means that SIPTA members share the same kind of very incomplete and severely deficient assessment that were made by Kyburg between 1959 and 2011. Section four will trace this ignorance directly to the bizarre decision by the editors of the Collected Writings of John Maynard Keynes (CWJMK, 1973) to allow an extreme, rabid, partisan advocate of precise probability to write an editorial foreword to volume 8 of the 1973 CWJMK edition of Keynes's A Treatise on Probability (TP, 1921).

It should be noted that Theodore Hailperin (1965, 1986, 1996; see also Hansen et al., 1993, 2000 which builds on Hailperin), who has made many contributions to imprecise probability, did not share Kyburg's very limited understanding of Keynes's contributions. However, no SIPTA member has carefully investigated Hailperin's much more positive assessment of Keynes, which will not be covered in this paper because I have covered it extensively in other papers available at SSRN.

\section{Kyburg's evaluation of Keynes's contribution to imprecise probability}

Consider the following statement made by Henry E Kyburg in his 1999 ISIPTA article, titled "Interval Valued Probabilities". It is representative of an assessment made by Kyburg about Keynes that did not vary for nearly 50 years starting in 1960. Kyburg's conclusion was that Keynes never provided any logical or mathematical structure for his approach to probability except to provide some "hints, suggestions, intuitions, ideas, etc.":

"It was J M Keynes who first forcibly argued that probabilities cannot be simply ordered. There are cases, he argued, in which the probabilities of the hypothesis $\mathrm{h}$ can be regarded neither as greater than that of hypothesis $\mathrm{k}$, nor less than that of hypothesis k, nor yet equal to that of hypothesis k. Although he did not provide a mathematical structure for his probability values, he did give us some hints..." (Kyburg, 1999).

It is very simple for anyone who has actually read Part II of the A Treatise on Probability, to see that Keynes did much more than just give out a few hints. Keynes laid out an exact and formal mathematical analysis of his approach to probability in Part II. Chapters 10-14 emphasize that the addition property of the mathematical laws of the calculus of probabilities is not the general case. He called his interval valued approach “approximation”. J M Keynes's mathematical structure for his approach to probability is given an exact, formal mathematical structure in chapters 15 (Keynes, 1921), 17 (ibid., pp. 186-194), 20 (ibid., pp. 234-237), 22 (ibid., pp .254-257), and 26 (ibid., sections 6-8 on pp. 307-315) of the TP. This approach is directly based on Boole's approach as presented by Boole in his (1854 The Laws of Thought). The reader is invited to read Arthmar and Brady (2010, 2016, 2017), Brady and Arthmar (2010, 2012) and /or Brady (1983, 1986, 1987, 1993, 1994, 1996, 1997, 2004a, 2004b, 2014) for the details of Keynes's imprecise approach to probability using interval valued upper and lower probabilities, which Keynes referred to as inexact measurement and approximation.

Kyburg believed that he was the first theorist to provide a mathematically structured theory of upper and lower probabilities or interval estimates for a logical theory of probability: "The idea of upper and lower probabilities, first developed for a logical interpretation of probability by Kyburg, has been independently developed in one form or another by various writers on subjective probability in addition to Smith (1961), Good (1962), Dempster (1967, 1968), and others. A further development on this idea is due to Levi (1974, 1985). Given an algebra of propositions, we may consider not only the upper and lower probabilities of each of these propositions, but a whole set... This representation of belief has the consequence that there are upper and lower probabilities associated with each proposition..." (Kyburg and Smokler, 1980).

This follows after Kyburg presents an extensive discussion of Keynes's contributions as having been very limited "views" (ibid., p. 5), "ideas" (ibid., p. 11, p. 18), "an intuitive notion" (ibid., p. 12), etc. Kyburg is completely ignorant of the fact that it was Keynes and Boole, not Kyburg, who was the first one who "...uses pairs of real numbers to characterize belief' (Kyburg and Smokler, 1980). This is followed by references to the work of Good (1962), Levi (1974), Smith (1961), Dempster $(1967,1968)$ and Shafer (1976). There are no references to Boole and Keynes. Contrary to Kyburg, the theory of upper and lower probabilities, the use of intervals, and the use of two numbers instead of one to denote the probability relation, was first developed in a formal, mathematical manner by Boole (Boole, 1854) on pp. 268339 of The Laws of Thought, by Keynes in (1908 and 1921) and by Hailperin in (1965, 1986). Kyburg's understanding of Keynes's contribution came from reading chapter III of Part I of the TP. It was extremely limited. Kyburg never read Part II of the TP. Again ,this reference to Keynes is taken from pages 30 and 34 of chapter III of the TP. Keynes's actual use of upper and lower valued interval probabilities in Part II in chapters 15-17 is ignored. 


\section{SIPTA member evaluations of Keynes mimic Kyburg's "evaluation"}

Consider the following summary of Keynes's contribution from T. Seidenfeld in (2004):

"This setting for uncertainty is different from the canonical Bayesian decision theory of expected utility, which uses Arthmar a singleton set, just one probability function to represent a decision maker's uncertainty. Justifications for using a non- and Brady trivial set of probabilities to depict uncertainty date back at least a half century (Good, 1952) and a foreshadowing of that not idea can be found even in Keynes (1921), where he allows that not all hypotheses may be comparable by qualitative mentioned probability - in accord with, e.g., the situation where the respective intervals of probabilities for two events merely in the overlap with no further (joint) constraints, so that neither of the two events is more, or less, or equally probable compared with the other." (Seidenfeld, 2004).

This assessment is the same as Kyburg's and is limited to chapter III of the TP. Seidenfeld never covered Part II of the TP in making his evaluation above of Keynes's contribution. The reference to Keynes is taken from pages 30 and 34 of chapter III of the TP. Keynes's actual use of upper and lower valued interval probabilities in Part II in chapters 15-17 is ignored. Consider the following contribution by Schervish et al. (2003).

"This paper offers a comparison among three decision rules for use when uncertainty is depicted by a non-trivial, convex set of probability functions P. This setting for uncertainty is different from the canonical Bayesian decision theory of expected utility, which uses a singleton set, just one probability function, to represent a decision maker's uncertainty. Justifications for using a non-trivial set of probabilities to depict uncertainty date back at least a half century [4] and a foreshadowing of that idea can be found even in [7], where he allows that not all hypotheses may be comparable by qualitative probability_in accord with, e.g., the situation where the respective intervals of probabilities for two events merely overlap with no further (joint) constraints, so that neither of the two events is more, or less, or equally probable compared with the other" (Schervish et al., 2003; Seidenfeld et al., 2003).

Again, this reference to Keynes [4] is taken from pages 30 and 34 of chapter III of the TP. Keynes's actual use of upper and lower valued interval probabilities in Part II (Keynes, 1921) in chapters 15-17 is ignored ,as well as Keynes's position, presented in chapters 10-14, that the addition law (additivity axiom) is not general, but a special case.

Consider the following contribution of Enrique Miranda in (2008) in his footnote 11:

" ${ }^{\text {"11 }}$ One of the first to talk about the presence of imprecision when modeling uncertainty was Keynes in ..., although there were already some comments about it in earlier works by Bernoulli and Lambert.... Keynes considered an ordering between the probability of the different outcomes of an experiment which need only be partial. His ideas were later formalized by Koopman in .... Other works in this direction were made by Borel..., Smith ..., Good..., Kyburg ... and Levi .... In 1975, Williams ... made a first attempt to make a detailed study of imprecise subjective probability theory, based on the work that de Finetti (1985) had done on subjective probability ... and considering lower and upper previsions instead of precise previsions. This was developed in much more detail by Walley in ..., who established the arguably more mature theory that we shall survey here" (Miranda, 2008).

Miranda's assessment and understanding of Keynes's contribution is that of a reader who has covered pages 30-34 of chapter III of Part I of the TP. The belief that it was Koopman (1940a, 1940b, 1940c) who developed Keynes's undeveloped intuitions about interval valued probability lies at the heart of SIPTA evaluations of Keynes Miranda's understanding of Keynes's contributions is the same as that expressed by Kyburg. Keynes's “ideas" are fully developed both mathematically and logically in Part II of the TP. Keynes bases his interval valued approach on Boole's specification on pp. 268-339 of The Laws of Thought of upper and lower probabilities .Of course, Keynes is working with imprecise and indeterminate probabilities in Part II of the TP. His work on imprecise probability also takes place on pp. 354-359 of the TP in Part V.

Consider the following assessment made by Zappia in 2015 in a footnote:

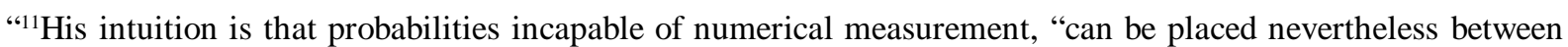
numerical limits" so as to make "a great number of comparisons or appropriate measurements become possible". Thus, Keynes's concern with unmeasurable probabilities can be given operational content, as in the works of Koopman (1940) and Good (1962) that inspired the developments of indeterminate, but interval-valued probabilities (Levi, 1980). On these usually disregarded origins of Keynes's discussion of probability see Brady and Arthmar (2012); Zappia (2015).

Zappia's confusion here is about what it was that Keynes had actually accomplished in the TP. It is clear that his error occurs because he never read Part II of the TP. He takes a small part of one page out of context from p. 160 of the TP and presents it as Keynes's contribution. Keynes's technical contribution is on pp.161-163. 
Keynes didn't just have some intuitions about the possibility of interval valued probability. Keynes operationalized his concerns in his 1908 Cambridge Fellowship Dissertation and in Part II of the TP long before Koopmans and Good considered interval valued probability. Koopman's understanding of Keynes comes only from chapter III.

Keynes operationalized interval valued probability long before the works of Koopman (1940) and Good (1962) that inspired the developments of indeterminate, but interval-valued probabilities (Levi, 1980). Zappia's citation of Brady and Arthmar makes no sense because Brady and Arthmar showed explicitly, and in great detail that Keynes had operationalized his approach in 1921 using an explicit mathematical approach on pp.161-163 and 186-194 of the (TP, 1921). Again, Zappia's reference to Keynes is mainly based on exactly the same material used by Koopman and then Kyburg, which is from pages 30 and 34 of chapter III of the TP. Keynes's actual use of upper and lower valued interval probabilities in Part II of the TP is ignored.

\section{The 1973 Braithwaite foreword concerning the TP}

$\mathrm{R}$ Braithwaite's editorial foreword is aimed at convincing potential readers that there is nothing in the book that is relevant as regards modern approaches to probability. Braithwaite was a rabid Ramseyian who constantly attacked the intellectual foundations of Keynes's approach during his entire life. I can find no evidence that he actually read the book that he was critiquing except for pp. 30-34 of the TP.

Consider the following claims made by Braithwaite. It is interesting that in his page 9 of foreword he gets nothing correct.

Braithwaite's claims are quite puzzling, indeed. In a 1931 paper, examined by Brady (2016), Braithwaite made the false claim that it was Richard Jeffreys who had first put forth a logical theory of probability in 1919, two years before Keynes did in 1921.Now this deliberately ignores the fact that Bertrand Russell had made extensive use of Keynes's 1908 Second Fellowship dissertation at Cambridge University, England in a book published in 1912, titled, The Problems of Philosophy:

"I have derived valuable assistance from unpublished writings of GE Moore and J M Keynes: from the former, as regards the relations of sense-data to physical objects, and from the latter as regards probability and induction. I have also profited greatly by the criticisms and suggestions of Professor Gilbert Murray" (Russell, 1912). Of course, Keynes's logical theory of probability is discussed in Russell's book in 1912, which happened seven years before the publication of the Wrinch-Jeffreys article.

Forty-two years later, Braithwaite is more subtle in his misrepresentation of Keynes's contribution. He merely insinuates that Jeffreys was first. Braithwaite finally acknowledges that Russell's book incorporated a discussion "...to some of his ideas..." (Braithwaite, 1973) although “... but (except for an article by Dorothy Wrinch and Harold Jeffreys in 1919, which Keynes had not seen) the Treatise contains the first publication of .... A logical probability relationship..." (Braithwaite, 1973).

Of course, there is no "except". Keynes's work was acknowledged in 1912 by Russell explicitly as regards specific work done by Keynes in "....probability and induction" and not as the very vague "... some of his ideas" as claimed by Braithwaite.

However, very quickly, Braithwaite starts making claims for which he provides absolutely no evidence at all, but simply piles one empty assertion on top of another:

"Keynes wrote the Treatise at a time when mathematicians were discovering the conditions required for an axiom set in any field to be formerly satisfactory; and the axiomatic development (in Part II of the Treatise) of the theorems of the probability calculus has serious formal defects. Keynes insisted that most probability relationships are not measurable, and indeed that many pairs of probability relationships are incomparable so that the set of all probability relationships cannot be arranged in simple one -dimensional order between the two extremes of certainty of truth and certainty of falsehood...Keynes's thesis that some probability relationships are measurable and others unmeasurable leads to intolerable difficulties without any compensating advantages." (Braithwaite, 1973)

Of course, contrary to the false intellectual assessment of Keynes's work presented by Braithwaite above, Keynes's TP logical theory of probability approach leads explicitly to imprecise, interval valued probability using upper and lower probability bounds to define non-additive probabilities. These non-additive probabilities, as well as Keynes's decision weight approach represented by his c coefficient of chapter 26, is concerned with the representation of uncertainty using inexact measurement and approximation which it is simply impossible to analyze with Ramsey's additive, linear approach. 
Braithwaite claims that the ... axiomatic development (in Part II of the Treatise) of the theorems of the probability calculus has serious formal defects. I can find no such defects in Part II of the TP at all. Braithwaite fails to specify or enlighten the reader about where such "serious formal defects" appear. What chapters is he talking about? In what sections of each chapter do these so called, alleged defects take place? What are the page numbers of the TP, where these so called "serious formal defects" appear. Is it chapter 10 or is it chapter 17 ? Could it be chapter 13 or 14 ? Braithwaite is completely silent on where these so called errors appear. Actually, there are no errors. The "errors" are really figments of Braithwaite's imagination.

Braithwaite's foreword can only lead to a decision on the part of a reader of Braithwaite's foreword to skip all of Part II of the TP because it is erroneous and error filled. This apparently is what has been happening since 1973.

The fact of the matter is that Braithwaite never ever actually read Part II of the TP. From his statement above, he appears to have read only pages 30 and 34 of the TP in chapter III, which is the standard approach taken by philosophers, historians, psychologists and economists to the TP.

Many years ago, I was contacted by some students at Cambridge University, England regarding Brady (2004a, 2004b). They informed me that all students seeking or expressing an interest in working on Keynes were required to read the 1973 CWJMK version of the TP in their classes. Of course, reading Braithwaite's completely erroneous assessment would seriously damage and undermine the message that Keynes was trying to convey about the importance of imprecise probability in decision making in general and decision making in particular in economics and finance, since it is impossible to deal with the uncertainty problem except by using either interval valued probability or decision weights. Braithwaite's very serious, intentional, intellectual misrepresentation of Keynes's work, engaged in order to advance F. Ramsey's competing, precise probability approach, which Braithwaite was a rabid adherent of, explains the total confusion emanating from the publications of Cambridge University associated economists and philosophers over the last 45 odd years, starting with E R Weintraub's confused 1975 History of Political Economy paper, with its confused and confusing assessment linking Keynes and Shackle, when, in fact, the systems they present are diametrically opposed, given Shackle's rejection of all theories of probability and his advocacy of a theory of possibility as a replacement for probability. Unfortunately, there is much more misrepresentation by Braithwaite.

Braithwaite claims the following:

“A more serious criticism of Keynes's theory is that it supposes that the logical interpretation of 'probability' applies to every field in which the term is used... But to show that a frequency theory will not explain the sense of "probability ' used in the context of rational belief does not show that it cannot adequately explain the probabilities which occur within scientific statements, e.g., that the probability of a radium atom disintegrating within 1622 years is $1 / 2$ (which is what physicists mean by saying that 1622 years is the 'half-life' of a radium atom). These propositions are undoubtedly empirical and so present insuperable obstacles to being incorporated into a logical theory of probability. Keynes never explicitly discusses such probabilities...." (Braithwaite, 1973).

Of course, Keynes easily showed how such probabilities, for example in chapters 8, 16 (pp. 172-174 dealing with Faraday and Maxwell) and 32, can easily be integrated into a logical theory of probability.

(The reader should note that Keynes is not dealing with this problem in chapter 24 of the TP , as falsely claimed by Braithwaite (Braithwaite, 1973, p. xviii). Chapter 24 is concerned with epistemological versus ontological uncertainty, where Keynes makes it clear that his concept of logical probability emphasizes epistemological uncertainty and not ontological uncertainty):

"Whilst no general criterion of choice seems to exist, where of two alternative classes neither includes the other, it might be thought that where one does include the other, the obvious course would be to take the narrowest and most specialized class. This procedure was examined and rejected by Venn; though the objection to it is due, not, as he supposed, to the lack of sufficient statistics in such cases upon which to found a generalization, but to the inclusion in the class-concept of marks characteristic of the proposition in question, but nevertheless not relevant to the matter in hand. If the process of narrowing the class were to be carried to its furthest point, we should generally be left with a class whose only member is the proposition in question, for we generally know something about it which is true of no other proposition. We cannot, therefore, define the class of reference as being the class of propositions of which everything is true which is known to be true of the proposition whose probability we seek to determine. And, indeed, in those examples for which the frequency theory possesses the greatest prima facie plausibility, the class of reference is selected by taking account of some only of the known characteristics of the quaesitum, those characteristics, namely, which are relevant in the circumstances. In those cases in which one can admit that the probability can be measured by reference to a known truth-frequency, the class of reference is formed of propositions about which our relevant knowledge is the 
same as about the proposition under consideration. In these special cases we get the same result from the frequency theory as from the Principle of Indifference. But this does not serve to rehabilitate the frequency theory as a general explanation of probability, and goes rather to show that the theory of this Treatise is the generalized theory, comprehending within it such applications of the idea of statistical truth-frequency as have validity.

'Relevance' is an important term in probability, of which the meaning is readily intelligible. I have given my own definition of it already. But I do not know how it is to be explained in terms of the frequency theory. Whether supporters of this theory have fully appreciated the difficulty I much doubt. It is a fundamental issue (Keynes, 1921).

In chapter 32 in sections 5 and 6, pp. 396-400, Keynes makes it clear that he will accept any statistical frequency statement if it passes the Lexis-Q test for stability (constancy of the answer as in the radium example used by Braithwaite).

Let us actually make use of Keynes's logical relation between conclusions and relevant evidence, $\mathrm{P}$, where, a, is the conclusion and $\mathrm{h}$ represent the different evidence statements in the form of propositions.

Let $h_{1}$ represent a proposition concerning frequent events; let $h_{2}$ represent a proposition concerning infrequent events; let $h_{3}$ represent a proposition about non frequent events. Then $P\left(a / h_{1}, h_{2}, h_{3}\right)$, where there is no relevant $h_{2}$ and $h_{3}$ evidence, reduces to $P\left(a / h_{1}\right)=1 / 2$ for the probability of the decay of a radium atom. Furthermore, $V\left(a / h_{1}\right)=1$, given that all of the available evidence establishes this probability to be a constant(stable value) satisfying the Lexis-Q test for stability.

Braithwaite, who ,like Ramsey ,had no idea that Keynes's objective ,logical probability relations are similarity relations between a and the $h_{\mathrm{i}},(i=1, \ldots, n, n+1 \ldots)$, based on analogy, pattern recognition, and resemblance, simply does not know what he is talking about when he claims the following:

“... and in a paragraph in which he speaks of probability being 'relative' in a sense to the principles of human reason ...he throws over entirely his doctrine of specific objective probability -relations" (Braithwaite, 1973).

Of course, Keynes's comment on p. 32 (p. 35 of the 1973 edition) needs to be read in connection with his assessment of the extremely close connection between probability and similarity on p. 36 which Keynes formally developed in Part III of the TP. However, neither Ramsey not Braithwaite, Ramsey's disciple, ever read Part III.

The only conclusion that is possible from the examination of Braithwaite's editorial introduction to the 1973 CWJMK's A Treatise on Probability, Volume 8, is to its purpose is to undermine any serious consideration of the soundness of Keynes's imprecise and non-additive approach to probability on the part of the reader. Braithwaite was a fanatical partisan of Ramsey's competing approach to probability that is precise and additive.

It is clear that Skidelsky (1992, 2010), O'Donnell (2012, 2014); Carabelli (1995) read this version of the TP and incorporated serious and severe error into their all of their work. This would explain Skidelsky's rejection (1992) of Keynes's logical theory of probability and his rejection of Keynes's definition of uncertainty on p. 148 of chapter 12 in footnote 1, that uncertainty is a function of the Evidential Weight of the Argument.

“Consider Braithwaite's paraphrase of Ramsey’s constant argument that

“On Keynes's theory it is something of a mystery why the probability relations should be governed by the probability calculus.

The answer is really quite simple-for any reader of the TP who has covered Part II of the TP. Ramsey and Braithwaite never covered Part II. First, the " non numerical " interval estimates will not be governed by the probability calculus because interval valued probability is non additive. Second, numerical probability calculations, such as the blue-green taxi cab problem of Tversky and Kahneman, will only satisfy the probability calculus if the weight of the evidence, w, is equal to 1 , where $\mathrm{w}$ is defined as a mapping onto the unit interval between 0 and 1 and $\mathrm{w}$ measures the relative completeness of the available, relevant evidence upon which the probability estimates are to be calculated.

Ramsey's intellectual mess of the one page of Part II that he apparently "read" starts as the following claim:

“...it is utterly obscure why Mr. Keynes’s mysterious logical relations should obey them" ${ }^{11}$ (Ramsey 1931, p.45 in Kyburg and Smokler,1980).

The footnote attached, footnote 11,is a repeat of Ramsey's intellectual mess of failing to grasp what an interval valued probability in his 1922 unrefereed Philosophical Magazine article:

“It appears in Mr. Keynes' system as if the principal axioms-the laws of addition and multiplication -were nothing but definitions" (Ramsey 1931, p.45 in Kyburg and Smokler, 1980). 
Now Keynes makes it clear in Part II that he does not consider the additivity axiom, that all probabilities must sum to 1, general.Russell,in his review ,does an excellent job in covering why Keynes's "non-numerical "probabilities do not satisfy the addition property except as a special case. Ramsey apparently NEVER realized in his lifetime that Keynes probabilities were imprecise. In 1923 in his Apostles Society presentation, titled Induction: Keynes and Wittgenstein, we find Ramsey claiming that "... we have the equally simple solution that this lies in their following certain logical probability relations, equally mysterious and difficult to identify...I think that both these simple solutions are wrong..." (Ramsey, 1923, p. 300; in Gaspard, 2014, p. 142).

Clarke makes the following assessment:

"This concerns his apparent shift of view in 1931, when he responded to criticism of his theory of probability from Frank Ramsey....personal sympathy may explain the tone which he adopted in a review of Ramsey's ...published papers. But can it explain Keynes's capitulation?," So far I yield to Ramsey-I think he is right.", Keynes wrote...." (Clarke, 2005).

Of course, there was no capitulation on Keynes's part .Keynes acknowledged that Ramsey's betting quotient Dutch book approach strengthened the logical foundations of precise probability and degrees of belief, but not imprecise probability and rational degrees of belief.

Cheryl Misak (2020a) simply repeats a number of confusions she has picked up from the Braithwaite view of Keynes. Nowhere in the TP is there anything related to a" ... knowledge of probabilistic truth." (Misak, 2020a). Or

"There is one true probability-an objective relation" (Misak, 2020a).

Or Keynes’s “....unmeasurable, non-numerical probabilities” (Misak, 2020a).

Contrary to Misak's belief that "He shook Keynes's confidence in his newly published probability theory”, (Misak, 2020a, see also Misak, 2016 and Misak, 2020b), Keynes realized that Ramsey was simply ignorant about his approach. For Keynes to have considered engaging Ramsey publicly in discussion necessitated Ramsey first having demonstrated to Keynes that he understood what Keynes 's theory was all about. He never did that. So Keynes never responded to Ramsey (1922, 1926, and 1978). Similarly with Braithwaite (1973). Braithwaite never demonstrated to Keynes that he understood Keynes's theory of imprecise probability. So Keynes never responded to Braithwaite.

The fundamental problem confronting Ramsey and Braithwaite in their intellectual struggle with Keynes's book is that they needed to have been able to read Part II of the TP. If Ramsey and Braithwaite had been able to read Part II, I would not be writing this article because Braithwaite would never have written his editorial foreword. See Zabell (1991, 2005) for an example of a philosopher who accepts most of Braithwaite's “views”about Keynes's contributions.

\section{Conclusion}

The TP is the foundation for the GT's concepts of uncertainty and the theory of Liquidity Preference. Uncertainty and Liquidity Preference (LP) is the foundation for Keynes's theory of the rate of interest. The foundation of Keynes's concept of uncertainty in the GT is the non (sub) additive view of probability expressed explicitly in Part II of the TP as inexact measurement and approximation, which also appears in Part V of the TP and in the General Theory in chapter four on pp. 39-40 and pp. 43-44. This means that the GT and TP are intertwined. The belief that there is some kind of hazy, unclear connection between the TP and the GT is what results when readers have not read and absorbed Part II of the TP or read the exchanges between Keynes and Townshend, which is the only correspondence after the GT was published in 1936 that deals with the TP and GT. Note that Keynes's correspondence with Tinbergen from $1938-1940$ was taking place simultaneously with the correspondence in 1938 with Townshend. It is obvious from this that the core disagreement between Keynes and Tinbergen is over the use of precise probability (Tinbergen, who wants to use the normal distribution) versus imprecise probability (Keynes).

All current academic assessments of the TP are incorrect because all such assessments ignore the fundamental foundations of Part II of the TP. The idea that Keynes had a few intuitions, or hints, or ideas about the need for nonmeasurable probabilities (interval valued probabilities), or made a few suggestions and offhand comments, has no support once Part II of the TP is fully integrated. Keynes's contribution to interval valued probability, both indeterminate (chapters 15-17, 20, 22 of the TP) and imprecise (chapter 29) probabilities, far, far exceeds the small one paragraph discussions on pages 30 and 34 of chapter III used by Koopman and Kyburg.

Recently, Bradley's (2019) contribution in the Stanford Encyclopedia of Philosophy claims that Keynes's contribution to imprecise probability was his diagram presented on page 39 (page 42 of the CWJMK 1973 version) of the TP (see also 
Carabelli (1994, 1995)). This represents a major step back for SIPTA regarding Keynes, since this diagram underlies the unanimous Keynesian Fundamentalist position that Keynes's contribution was, at best, an ordinal theory of probability with very limited applicability. Keynesian Fundamentalists explicitly deny that Keynes's contribution had anything to do with an interval theory of probability for their viewpoint (Zappia, 2015).

The only mention of Keynes's name in the 2015 SIPTA (July) meeting is the following mention by G Wheeler, which is not contained in the conference volume:

"In this tutorial we will introduce several topics in the foundations of imprecise probabilities through a review of key historical figures, including John Maynard Keynes, BO Koopman, and IJ Good, Henry Kyburg, Terrence Fine and Isaac Levi, and their reactions to the subjectivist-rationalist tradition associated with Ramsey, de Finette, and Savage, and the later developments associated with Peter Williams and Peter Walley” (Wheeler, 2015, p.24).

However, this sounds exactly like the Kyburg view of Keynes. The conclusion reached is that SIPTA's view of Keynes's contributions in 1999 were identical to SIPTA's view in 2015. Edgeworth's two reviews (1922a, 1922b) represent a superior understanding of Keynes which have been ignored for one hundred years.

Braithwaite's fatal error was to accept at face value Ramsey's false claims about Keynes's use of propositions in 1922 ["First, he thinks that between any two non-self-contradictory propositions there holds a probability relation (Axiom I), for example between 'My carpet is blue' and 'Napoleon was a great general'..." (Ramsey,1922)] and 1926[“Mr Keynes accounts for this by supposing that between any two propositions, taken as premiss and conclusion, there holds one and only one relation of a certain sort called probability relations..." (Ramsey,1926 (Kyburg and Smokler,1980)). These claims directly conflict with Keynes's analysis of the specific argument form his a and h propositions must have on pp.4-6 of the TP. Since Ramsey 's errors are the foundation for both of his critiques, there is no correct point made by Ramsey in either 1922 or 1926.

\section{References}

Arthmar, Rogério. and Brady, Michael Emmett. (2016). The Keynes-Knight and the de Finetti-Savage's approaches to probability: An economic interpretation. History of Economic Ideas. XXIV(1), 105-124.

Arthmar, Rogério. and Brady, Michael Emmett. (2017). Reply to Feduzi, Runde, and Zappia. History of Economic Ideas. XXV(1), 55-74.

Boole, George. (1854). An Investigation of the Laws of Thought on Which are Founded the Mathematical Theories of Logic and Probability. New York: Dover Publications, [1958].

Borel, Emile. (1924). A propos d'un traité de probabilités.Revue Philosophique de la France et de l'Étranger, T. 98 (JUILLETADÉCEMBRE,1924), 321-336

Bradley, Seamus. (2019). “Imprecise Probabilities”, The Stanford Encyclopedia of Philosophy (Spring 2019 Edition), Edward N. Zalta (ed.), Supplement to Imprecise Probabilities-Historical appendix: Theories of imprecise belief, https://plato.stanford.edu/archives/spr2019/entries/imprecise-probabilities/

Brady, M.E. (1983). The Foundation of Keynes' Macroeconomics: His Logical Theory of Probability and its Application in the General Theory. U. C. Riverside, Dissertation (July).

Brady, M.E. (1986). Reviewing the Reviewers of J.M. Keynes's A Treatise on Probability: How most of them got it all wrong. Unpublished paper.[Published in 2016 as Reviewing the Reviewers of J.M. Keynes's A Treatise on Probability: Ignorance is Bliss. Xlibris Press; Philadelphia ,Pennsylvania].

Brady, M.E. (1987). J. M. Keynes' theory of evidential weight: Its relation to information processing theory and application in the general theory. Synthese. 71, 37-60.

Brady, Michael, E. (1993). J.M. Keynes' theoretical approach to decision making under condition of risk and uncertainty. The British Journal for the Philosophy of Science. 44, 357-376.

Brady, Michael, Emmett.(1994). On the application of J.M. Keynes's approach to decision making. International Studies in the Philosophy of Science. 8(1), 99-112.

Brady, Michael, Emmett. (1996). Decision making under risk in the treatise on probability: j.m. keynes' 'safety first' approach. History of Economics Review. 25, 204-210.

Brady, Michael, Emmett. (1997). Decision making under uncertainty in the treatise on probability: keynes' mathematical solution of the 1961 ellsberg two color, ambiguous urn ball problem in 1921, History of Economics Review, 26 136-142. 
Brady, Michael, Emmett. (2004a). J. M. Keynes’ Theory of Decision Making, Induction, and Analogy. The Role of Interval Valued Probability in His Approach. Xlibris Corporation.

Brady, Michael, Emmett. (2004b). Essays on John Maynard Keynes and .... Xlibris Corporation.

Brady, Michael, Emmett. (2014). A study of ramsey's extremely poor reading of chapter III of J. M. Keynes's A Treatise on Probability and the Refutations Made by J. M. Keynes and Bertrand Russell (February 17, 2014). Available at SSRN: http://ssrn.com/abstract=2397404

Brady, Michael Emmett and Arthmar, Rogerio. (2010). Aroad map for economists, logicians, philosophers, mathematicians, statisticians, psychologists and decision theorists seeking to follow the mathematical structure of keynes's approach to specifying lower and upper bounds for probabilities in the a treatise on probability, 1921 (1973). available at SSRN:http://ssrn.com/abstract=1618445

Brady, Michael Emmett and Arthmar, Rogerio.(2012). Keynes, Boole and the interval approach to probability. History of Economic Ideas. 20(3), 65-84.

Braithwaite, R.B. (1973). Editorial Foreword to A Treatise on Probability,Vol.8,CWJMK edition.London,Macmillan, pp. xiv-xxii).

Carabelli A. (1994). Keynes on mensuration and comparison. In K. Vaghn ,ed, Perspectives in the History of Economic Thought, Aldershot, Edward Elgar, pp. 204-238.

Carabelli, Anna. (1995). Uncertainty and measurement in Keynes: probability and organicness. In Dow, Sheila; Hillard,John, (eds.) Keynes, Knowledge and Uncertainty. Aldershot: Edward Elgar.

Clarke,P. (2005). J M Keynes 1883-1946:The best of both worlds. In (Mandler, P. and Pedersen, S.,eds), After the Victorians: Private Conscience and Public Duty in Modern Britain." Routledge; England, pp.173-190.

de Finetti, Bruno. (1985). Cambridge probability theorists. The Manchester School of Economic and Social Studies. 53, 348-363. Translated by Gianluigi Pelloni. Originally published in 1938.

Dempster, A.P. (1967). Upper and lower probabilities induced by a multivalued mapping. Annals of Mathematical Statistics. 38, 325-339.

Dempster, A.P.(1968). Upper and lower probabilities generated by a random closed interval.Annals of Mathematical Statistics. 39, 957-966.

Edgeworth, F. Y. (1922a). The philosophy of chance. Mind. 31(23), 157-185.

Edgeworth, F. Y. (1922b). Review of A Treatise on Probability. By John Maynard Keynes. JRSS,85,107-113.

Gaspard,Marion. (2014). Logic,rationality and knowledge in Ramsey's thought:reassessing 'human logic'. Journal of Economic Methodology. 21(2), 139-157.

Good ,I.J.(1962). Subjective probability as the measure of a non-measurable set, in: E. Nagel, P. Suppes, A. Tarski (Eds.), Logic, Methodology and Philosophy of Science, Stanford University Press, Stanford, pp. 319-329.

Hailperin, T. (1965). Best possible inequalities for the probability of a logical function of events. American Mathematical Monthly. 72, 343-359.

Hailperin, T. (1986). Boole's Logic and Probability. Amsterdam: North-Holland. $2^{\text {nd }}$ edition.

Hailperin, T. (1996). Sentential Probability Logic. Bethlehem: Lehigh University Press.

Hansen, P., Jaumard, B. \& de Aragão, M. P. (1993). Boole's Conditions of Possible Experience and Reasoning under Uncertainty. Relatório Técnico, DCC-12/93.

Hansen, P. et al. (2000). Probabilistic satisfiability with imprecise probabilities. International Journal of Approximate Reasoning. 24, 171-189.

Keynes, J.M. (1908). The Principles of Probability. 3 volumes. Keynes Papers, King's College, Cambridge University, England.

Keynes, J.M. (1921). A Treatise on Probability. Macmillan, London.

Keynes, J.M.(1973a). A Treatise on Probability. Macmillan, London. Volume 8.CWJMK edition of the A Treatise on Probability (with the editorial foreword of R. B Braithwaite,pp. xiv-xxii).

Keynes, J.M. (1973b). F. P. Ramsey. In Essays in Biography, CWJMK (pp. 335-346), vol. X, London: Macmillan for the Royal Economic Society (reprinted from The New Statesman and Nation, 3 October 1931). 
Kyburg, H.E., Jr. (1970). Probability and Inductive Logic. New York: Macmillan.

Kyburg, H.E., Jr. (1988). Uncertainty and the Conditioning of Beliefs. US Army CECOM Signals Warfare Directorate.92TRF-0003.

Kyburg, H.E., Jr. (1991). Knowledge Representation and Uncertainty in AI.Technical Report 395.U.S. Army CommunicationElectronics Command Grant DAAB10-87-K-022.

Kyburg, H.E., Jr. (1992). Getting fancy with probability. Synthese. 90,189-203.

Kyburg, H.E. Jr. (1995). Keynes as a philosopher. In Cottrell, A. F. \& Lawlor, M. S. (Eds.), New Perspectives on Keynes. Durham: Duke University Press.

Kyburg, H. E. Jr. (1999). Interval-Valued Probabilities.(SIPTA):http ://www.sipta.org . Levi, I. (1967). Gambling with Truth.

Kyburg,H.E., Jr. (2002). Don’t take unnecessary chances. Synthese, 132, 9-26.

Kyburg, H.E., Jr. (2003). Are there degrees of belief?. Journal of Applied Logic. 1, 139-149.

Kyburg, H.E., Jr. (2006). Belief, evidence, and conditioning, Philosophy of Science. 73, 42-65.

Kyburg,H.E., Jr.(2011). Logic, Empiricism and Probability Structures. In Fundamental Uncertainty: Rationality and Plausible reasoning. Edited by S.Brandolini and R.Scazzieri. Palgrave Macmillan,England, pp. 39-58.

Kyburg, H.E. Jr. and Smokler, H.E. (1964). Introduction. In Kyburg and Smokler, Studies in Subjective Probability. New York: Wiley.

Koopman, B. (1940a). The axioms and algebra of intuitive probability, Annals of Mathematics. 41, $269-292$.

Koopman, B. (1940b). The bases of probability, Bulletin of the American Mathematical Society. 46, 763-774.

Koopman, B. (1940c). Intuitive probabilities and sequences, Annals of Mathematics, 42, 169-187.

Levi, Isaac. (1974). On indeterminate probabilities. Journal of Philosophy, 71, 391-418.

Levi, Isaac. (1985). Imprecision and Indeterminacy in Probability Judgment. Philosophy of Science. 52, 390-409.

Miranda , Enrique. (2008). A survey of the theory of coherent lower previsions. International Journal of Approximate Reasoning. 48(June), 628-658.

Misak,C.(2016). The Subterranean influence of Pragmatism on the Vienna Circle: Pierce, Ramsey, Wittgenstein. Journal for the History of Analytical Philosophy. 4(5).

Misak,C.(2020a). Frank Ramsey: A Sheer Excess of Powers. Oxford:Oxford University Press.

Misak,C.(2020b). Pragmatic Philosophers:Let's just focus on the best we can do....(https://www.cbc.ca/radio/idea/ pragmatic-philosophers-let-s-just-focus-on — the-best-we-can-do-1.5524895.(April $7^{\text {th }}$ )

O’Donnell, Rod. (2012). Treatise on Probability. In The Elgar Companion to Post Keynesian Economics, ed. By J E King. England; Edward Elgar,pp.359-365.

O’Donnell, Rod. (2014). “Two Post-Keynesian Approaches to Uncertainty and Irreducible Uncertainty," in G. C. Harcourt and Peter Kriesler (eds.), The Oxford Handbook of PostKeynesian Economics. Volume 2: Critiques and Methodology. Oxford University Press, New York. pp. 124-142.

Ramsey, F.P. (1922). Mr. Keynes on Probability, Cambridge Magazine, XI, 1, (Jan) 3-5. Reprinted in British Journal of the Philosophy of Science, 40, [1989], 219-222.

Ramsey, F.P. (1926). Truth and probability. In Mellor, D. H (Ed.) Foundations: Essays in Philosophy, Logic, Mathematics, and Economics, London: Routledge \& Kegan Paul, [1978].

Schervish, M. J., Seidenfeld, T., Kadane, J. B. \& Levi, I. (2003). Extensions of expected utility theory and some limitations of pairwise comparisons. Proceedings of the Third International Symposium on Imprecise Probabilities and Their Applications, pp. 496-510.(ISIPTA 2003;pp.337-351).

Seidenfeld, T. (2004). A contrast between two decision rules for use with (convex) sets of probabilities: gamma-maximin versus E-admisibility, Synthese, $140,(1-2)$, pp. 69-88.

Shafer, G. (1976). A theory of statistical evidence. Foundations of Probability Theory, Statistical Inference, and Statistical Theories of Science, Vol. II, pp. 365-436. W. L. Harper and C. A. Hooker, eds., Reidel.

Skidelsky, R. (1992). John Maynard Keynes, Volume II: The Economist as Saviour 1920-1937. London: Macmillan. 
Skidelsky, R. (2010). The Social Market Economy Revisited. The Social Market Foundation. London, England.

SIPTA '15 (2015). Proceedings of the $9^{\text {th }}$ International Symposium on Imprecise Probability: Theories and Applications 20-24 July 2015, Pescara, Italy.

Smith, C.A.B.(1961). Consistency in statistical inference and decision (with discussion), Journal of the Royal Statistical Society. 23, 1- 37.

Wheeler,G. (2015). Introduction to the Philosophical Foundations of Imprecise Probabilities. Munich Center for Mathematical Philosophy, Ludwig Maximilians University Geschwister-Scholl-Platz 1, 80539 Munich.

Tversky,A. and Kahneman,D.(1982). Evidential impact of base rates.In D. Kaheman, P.Slovic and A. Tversky (eds.), Judgement Under Uncertainty: Hueristics and Biases.Cambridge: Cambridge University Press, pp.153-160.

Zabell, S.L. (1991). Ramsey, truth, and probability.Theoria, 57(3)(December), 211-238.

Zabell, S.L. (2005). Symmetry and its discontents. Cambridge: Cambridge University Press.

Zappia, Carlo. (2015). Keynes on probability and decision: evidence from the correspondence with Hugh Townshend. Forthcoming, History of Economic Ideas (SSRN;pp.1-13).

Cite this article as: Michael Emmett Brady (2021). How SIPTA overlooked Keynes's major contributions to imprecise probability and decision making, 1999-2019. International Journal of M anagement Research and E conomics. 1(3), 11-21. doi: 10.51483/ IJM RE.1.3.2021.11-21. 